\title{
Rail Corrugation of High-Speed Railway Induced by Rail Grinding
}

\author{
Xing Du $\mathbb{D}^{1},{ }^{1}$ Xuesong Jin, ${ }^{1}$ Guotang Zhao, ${ }^{2}$ Zefeng Wen, ${ }^{1}$ and Wei Li ${ }^{1}$ \\ ${ }^{1}$ State Key Laboratory of Traction Power, Southwest Jiaotong University, Chengdu 610031, Sichuan, China \\ ${ }^{2}$ China Railway Corporation, Beijing 100036, China
}

Correspondence should be addressed to Xing Du; duxing@my.swjtu.edu.cn

Received 11 January 2021; Revised 12 April 2021; Accepted 1 June 2021; Published 11 June 2021

Academic Editor: Traian Mazilu

Copyright ( $\odot 2021$ Xing Du et al. This is an open access article distributed under the Creative Commons Attribution License, which permits unrestricted use, distribution, and reproduction in any medium, provided the original work is properly cited.

\begin{abstract}
Rail corrugation is a common railway defect that involves diverse and complex factors. Rail grinding is also the most commonly used method to address corrugations. Through numerous irregularity tests and one-third octave frequency spectrum analyses, this study determined the characteristics and development process for rail corrugation on high-speed rail tracks. The vibration transmission properties of the grinding train were tested using the force hammer impacting method. Thereafter, using a simulation, the influence of the vertical vibration behavior of the grinding stone and the stiffness of the hydraulics were determined. Through a series of field tests and numerical simulations, this study revealed a clear correlation between rail corrugation and rail grinding and confirmed that the technical operation of rail grinding is closely associated with regular grinding marks at a wavelength of approximately $60 \mathrm{~mm}$ on rail surfaces. The combination of the natural vibration of the grinding stone (frequency of $60 \mathrm{~Hz}$ ) and an inappropriate operational process can aggravate the grinding marks on the rail surfaces, thereby forming an initial excitation of rail corrugation. Although a large number of irregularity tests are performed after rail grinding, these wavelengthfixing grinding marks can cause the formation and development of rail corrugation. Suggestions for improving the high-speed rail-grinding technology are also provided.
\end{abstract}

\section{Introduction}

Rail corrugation is one of the most significant problems faced by the railway industry worldwide, and it affects all types of railways. The formation and development of rail corrugation causes fierce vibrations in the structures of vehicles and tracks, noise [1], ground and building vibrations [2], reduction in the service life of the structural parts of vehicles and tracks [3], and reduction in vehicle ride comfort [4] and also affects the wheel/rail dynamic force [5]. In some cases, serious corrugation causes total destruction of vehicles and tracks. Corrugated rails result in considerable maintenance and replacement costs to transportation companies. Therefore, understanding the mechanism of corrugation production and growth is essential. The phenomenon of rail corrugation has been observed and studied for over 100 years. Substantial progress has been made in recognizing the mechanism of initial corrugation formation, and theoretical and experimental methods have been developed [6]. According to state-of-the-art reviews on rail corrugation, studies have focused on field investigations and laboratory experiments, as well as theoretical and numerical modeling [3].

Some researchers have used field observations and experiments to investigate the characteristics and causes of rail corrugation. In 2002, Sato et al. [7] discussed in detail the problem of rail corrugation in Japan. In 2003, Nielsen et al. [8] surveyed high-frequency train and track interaction, as well as the mechanism of nonuniformity in the magnitude of the tangent and the large radius curve along the wear of the rail running surface. In 2013, Li et al. [9] investigated the corrugation mechanism of rails for both the tangent and curved tracks of a metro with Cologne fasteners, including extensive measurements at sites and a numerical analysis. Jin et al. [3] investigated rail corrugation that occurred in metro lines of several Chinese cities beginning in 2010. The investigation included the measurement, analysis, and observation of rail corrugation characteristics, dynamic behavior of the metro tracks generating the corrugations, and an analysis of the corrugation mechanisms. 
Additionally, they discussed the essential conditions for the formation of rail corrugation and presented a detailed relationship between the corrugation characteristics and metro track characteristics.

In addition, scholars have proposed many calculation models to understand the mechanism of rail corrugation formation and development. These models can be divided into a frequency-domain theory [10-14] and a nonlinear time-domain theory of a corrugation analysis model [15-20]. In 1986, Frederick [21] proposed a linear frequencydomain theory of corrugation. In 1996, Hempelman and Knothe [22] presented an advanced linear model for the prediction of short-pitch corrugation, which considered that contact mechanics provided a contact filter that suppressed the growth of extremely short-wavelength corrugation. In 1997, Igeland and Ilias [23] proposed a corrugation growth prediction model based on nonlinear high-frequency vehicle-track interaction, which considers the factors of nonlinear contact force, nonlinear wheel-rail contact geometry, and high-frequency wheel-rail interaction. In 2006, Wen [24] proposed a rail corrugation calculation model based on the wear mechanism. The model considered a combination of a modified Kalker's non-Hertzian rolling contact theory, a rail material wear model, and the vertical and lateral coupling dynamics of half a passenger car and a curved track. This corrugation model is more complete and complicated than those previously reported.

According to these published studies, rail corrugation formation and development are caused by factors that include the pinned-pinned resonance and $\mathrm{P} 2$ resonance of a track [24-27], torsional vibration of a wheelset [28-30], passing speed of a vehicle [[31], [32]], and fastening system stiffness [33, 34]. Relationships between the structural characteristics of track and corrugation formation and development, including rail irregularities [35], track geometry defects [36], and sleeper distance [31, 37, 38], were also indicated. The last factor $[39,40]$ is the influence of rail plastic deformation as a possible saturation mechanism of corrugation growth.

In one study, rail grinding was found to be an important maintenance method for addressing rail corrugation, rolling contact fatigue, and wear [41]. In the 1970s, this technology was successfully used to control wheel-track contact forces and to reduce rail wear in Western Australia [42]. Tyfour [43] showed that corrugation could be completely removed from the deformed layer at its earliest formation when rail grinding was performed at the onset of steady-state wear behavior.

Considered together, all previous studies on rail corrugation and grinding technology have focused on the positive role of rail grinding to address rail corrugation. To the best of our knowledge, there are no reports on the possible negative effects of grinding on the development of rail corrugation. Through numerous irregularity tests and detailed analyses of rail corrugation, this study discusses the characteristics and development processes of rail corrugation in high-speed track systems and reveals a clear correlation between rail corrugation and rail grinding.

\section{Field Investigation on China's High- Speed Railways}

In this study, three high-speed railway lines in China with an operating speed of $300 \mathrm{~km} / \mathrm{h}$ were examined at 26 sites for rail track defects. The corrugations on the rail track surface at several sites were visible with the naked eye, as shown in Figure 1. According to the field observations, three sections (Sections A, B, and C) on the three railway lines were selected for analysis, including both tangent and curved sections (Figures 1-3). Section A is for trains traveling toward Beijing and has a curve radius of $7000 \mathrm{~m}$ in east China. Section B is a tangent section for trains traveling away from Beijing in southwest China. Section C describes trains traveling toward Beijing and has a curve radius of $10,000 \mathrm{~m}$ in the middle of China. Section A shows the rail surface several months after rail grinding, whereas Sections $\mathrm{B}$ and $\mathrm{C}$ show the rail surfaces several days after grinding.

The right-hand panels in Figures $1-3$ show the one-third octave wavelength of rail irregularities detected by a corrugation analysis trolley. Rail irregularities with wavelengths of 63 and $125 \mathrm{~mm}$ were observed in the left and right tracks in Section A, respectively. The maximum peak-to-peak value of rail corrugation was $0.08 \mathrm{~mm}$. The central wavelength, which consists of a dominant wavelength of $63 \mathrm{~mm}$ and a secondary wavelength of $125 \mathrm{~mm}$, indicated the presence of corrugations. The roughness level at a dominant wavelength of $63 \mathrm{~mm}$ exceeded $6 \mathrm{~dB}$, which is the roughness level limit set by ISO 3095-2005. The dominant wavelength in Section B was $63 \mathrm{~mm}$, and a wavelength of $50 \mathrm{~mm}$ was also detected. The maximum peak-to-peak roughness value was $0.06 \mathrm{~mm}$; in Section C, the dominant wavelengths of the left and right rails were $50 \mathrm{~mm}$. The maximum peak-to-peak value of corrugation was $0.05 \mathrm{~mm}$. Grinding treatment was applied to the three rail sections with the same type of rail grinder, and their one-third octave band spectra were consistent with the results from actual pictures.

The investigation revealed that, in addition to a number of tangent track sections, significant rail corrugation at wavelengths of $63 \mathrm{~mm}$ and $50 \mathrm{~mm}$ (as shown in Figure 2) was also present on the tangent sections connected to the ends of multiple curved sections, transitional curved sections, and circular curved sections, as shown in Figure 4. This indicates that the curved rail sections underwent grinding.

In addition to the above tested rail sections that experienced grinding, a nonground section (Section D) was examined to compare the ground and nonground track areas on the same side of the rail in the grinding boundary zone. Figure 5 shows the test results, and Figure 6 shows an actual photograph. Section $D$ is located in the same line as Section A.

The results show that rail corrugations with wavelengths of $63 \mathrm{~mm}$ and $125 \mathrm{~mm}$ were present in the ground area, whereas no rail corrugation was noticeable in the nonground area. The above observations and test results indicate the existence of various degrees of rail corrugation on the ground track. This corrugation was consistently 


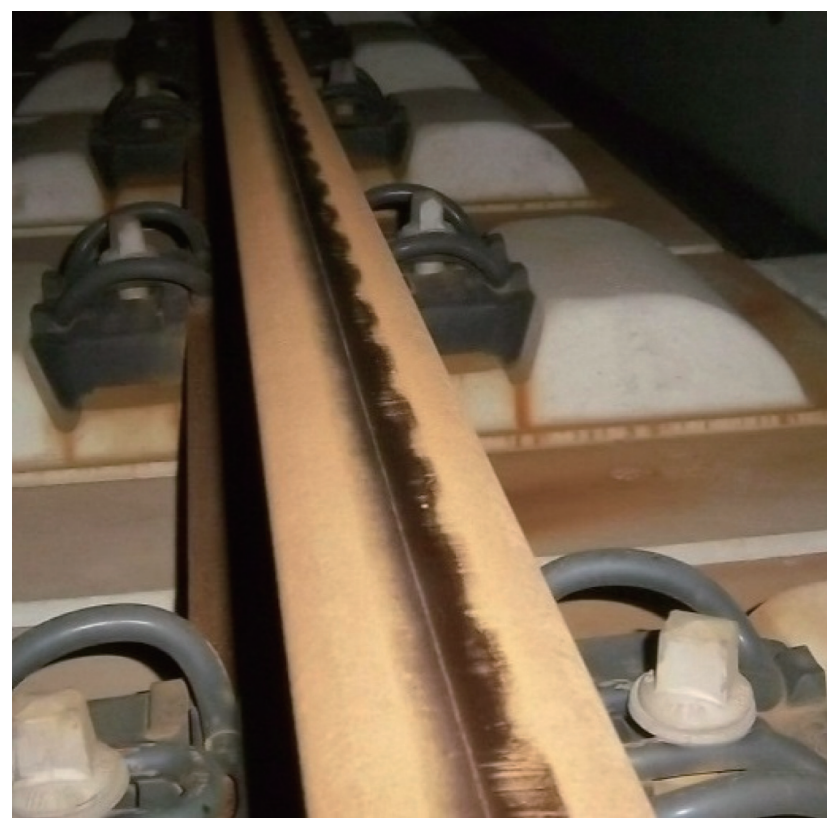

(a)

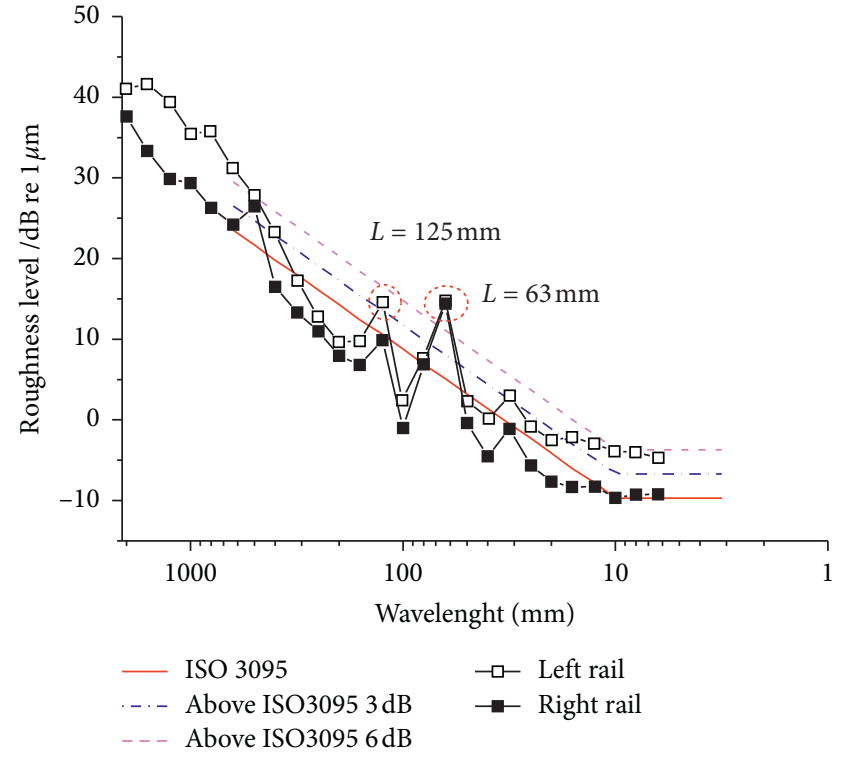

(b)

Figure 1: Picture and roughness spectra of rail corrugation in Section A.

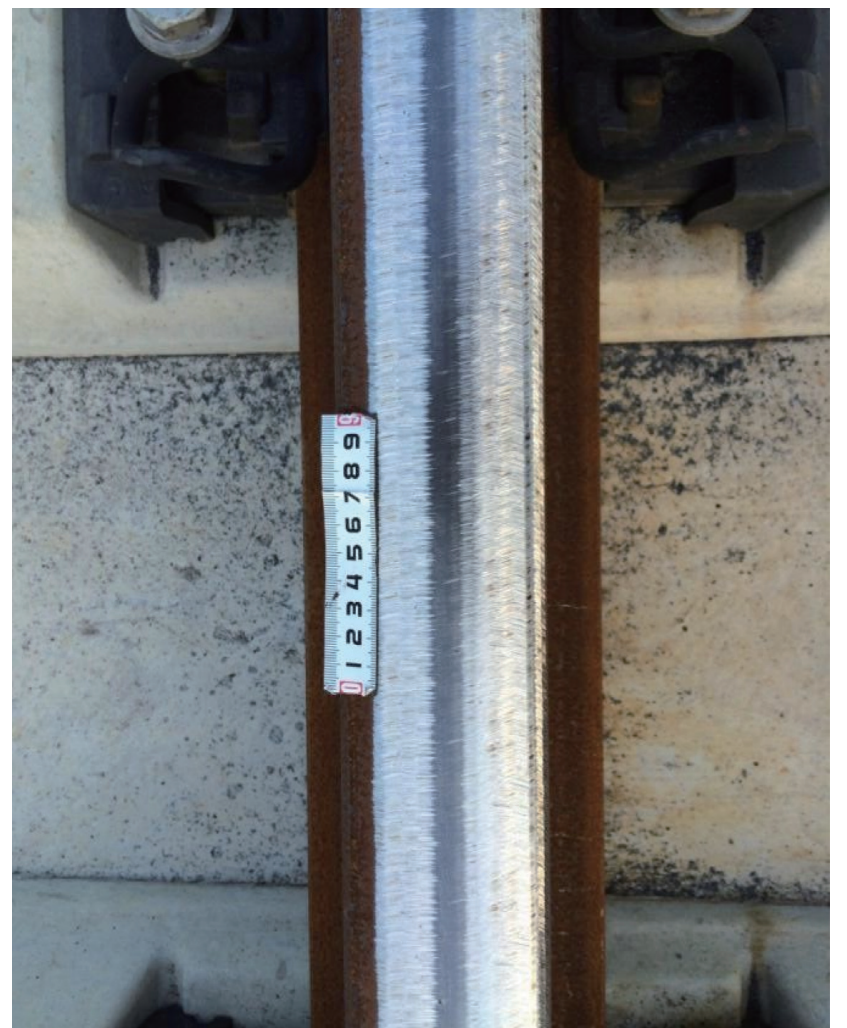

(a)

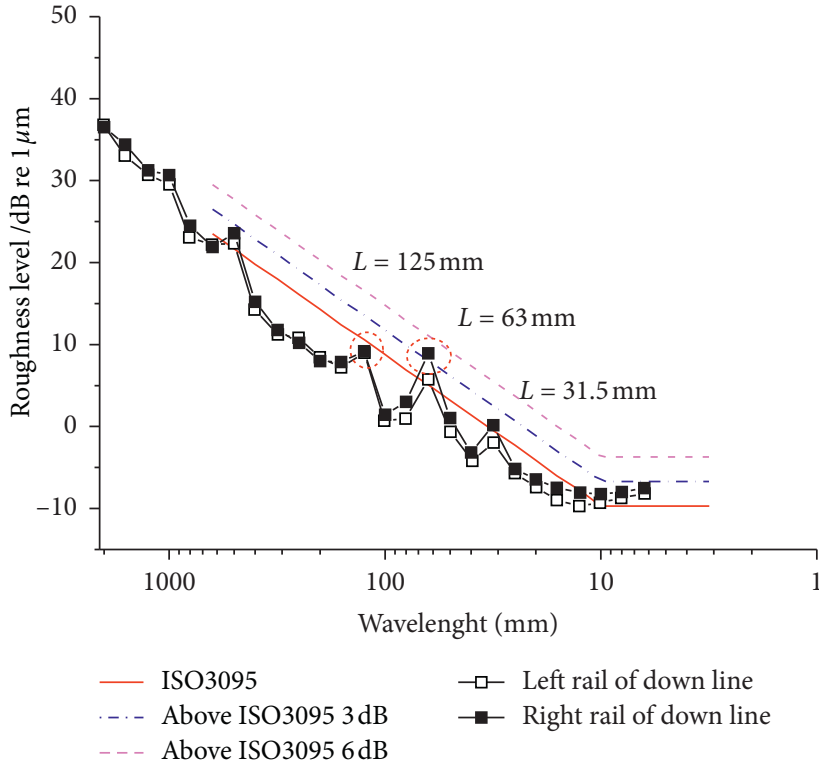

(b)

Figure 2: Picture and roughness spectra of rail corrugation in Section B. 


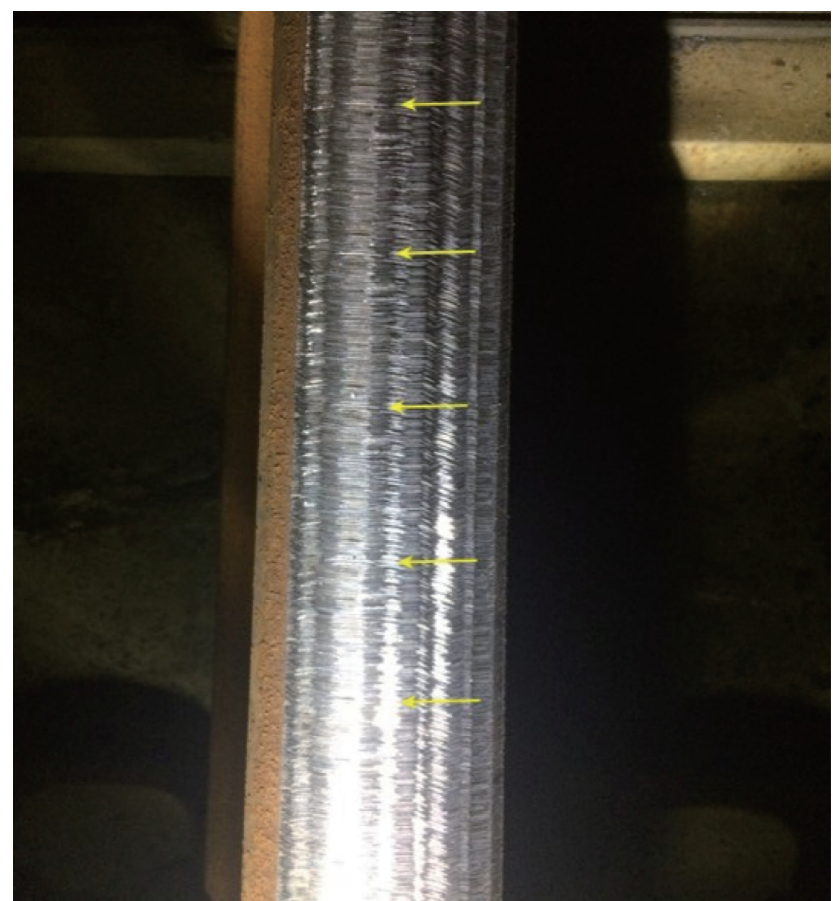

(a)

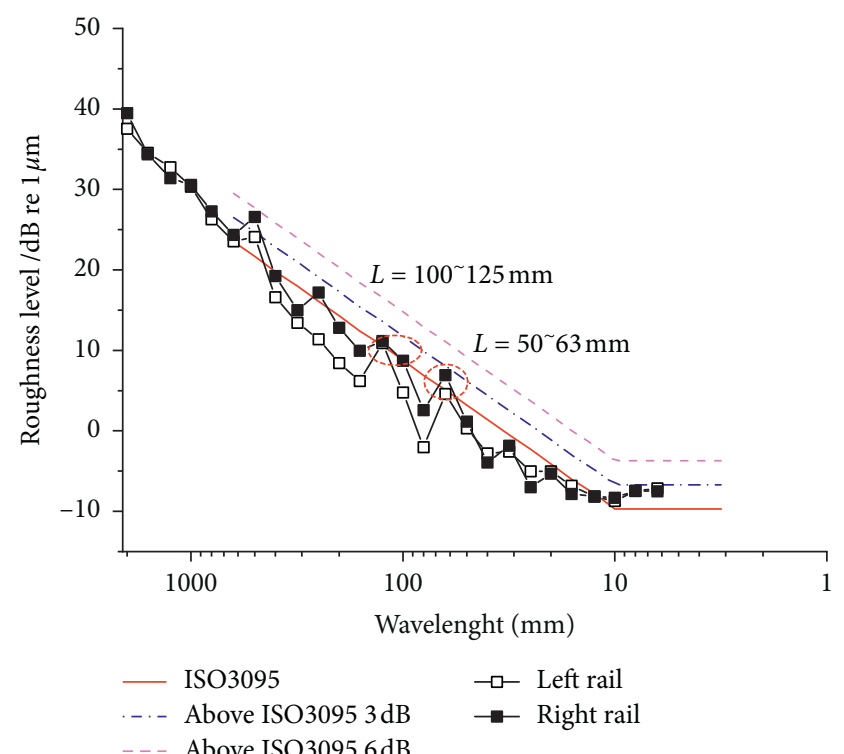

(b)

FIgURE 3: Picture and roughness spectra of rail corrugation in Section C.

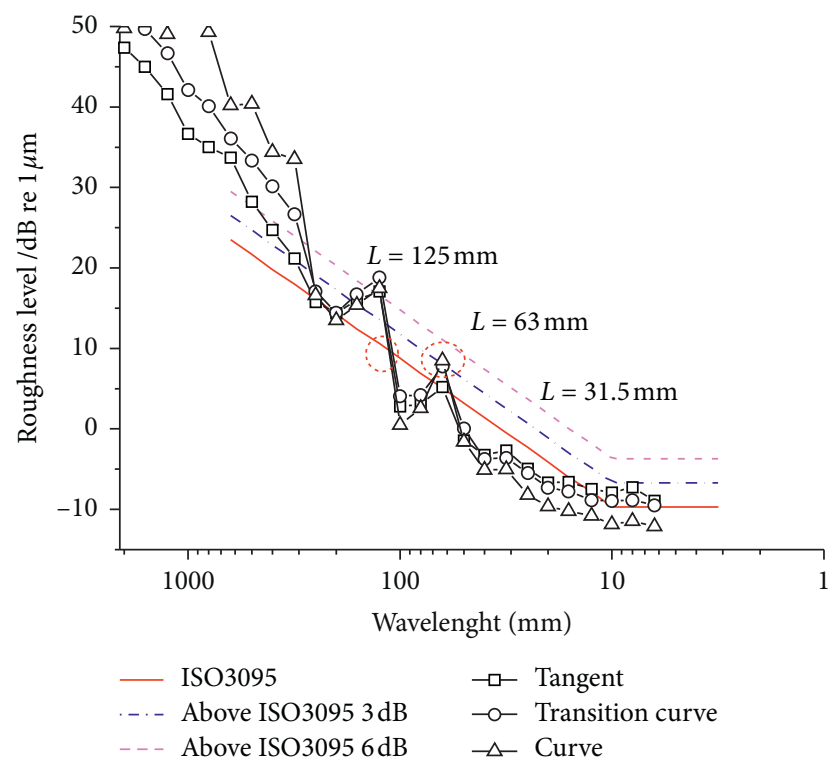

FIGURE 4: Roughness spectra of corrugation on high and low rails of curved tracks.

characterized by dominant wavelengths in the ranges of 50-63 $\mathrm{mm}$ and 100-125 $\mathrm{mm}$. In summary, rail corrugation was found on ground sections rather than on nonground sections. In addition, the same wavelength of regular scratch marks at $60-\mathrm{mm}$ intervals appeared on the rail surface after grinding. These sections were ground using the same type of grinder with 96 grinding stones.

\section{Dynamic Characteristic Simulation of the Rail Grinder}

Based on the above observations, a ground rail surface is more vulnerable to corrugation than a nonground rail surface. Therefore, the rail-grinding technology and the vibration properties and dynamic behavior of grinding 


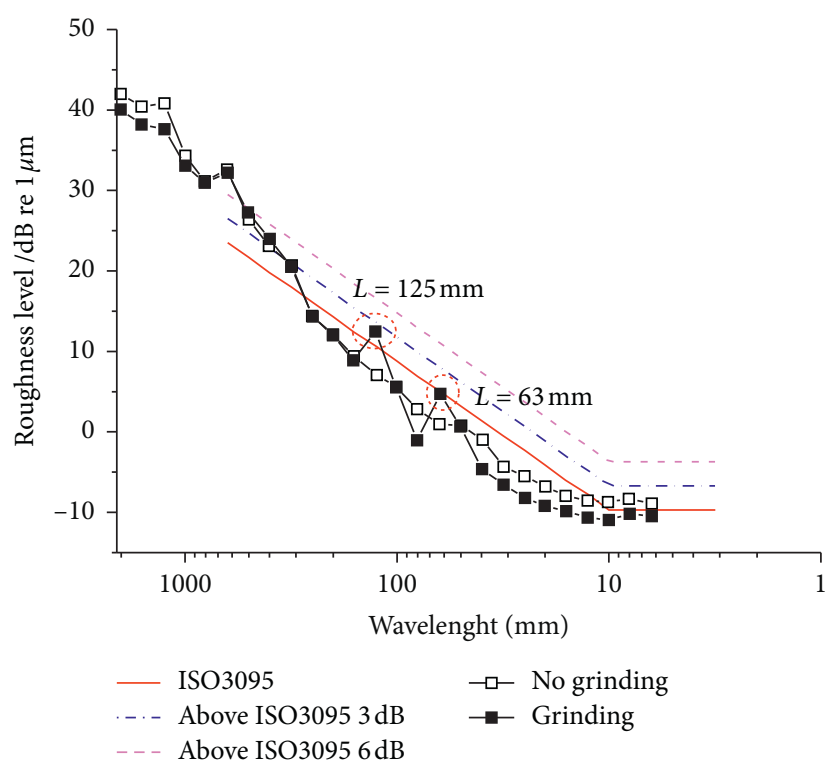

Figure 5: Comparison of roughness spectra in nonground and ground parts of the same rail.

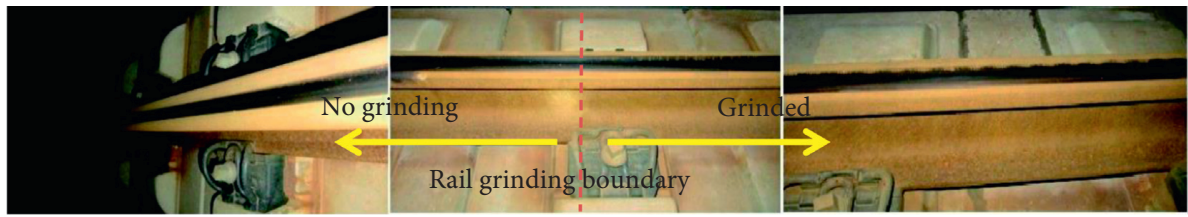

Figure 6: Picture of section with nonground and ground parts of the same rail in Section D.

trains were examined and analyzed by simulation tests. This is helpful in clarifying the relationship between the grinding operation and rail corrugation development.

3.1. Analysis of the Rail-Grinding Procedure. Rail-grinding technology using grinding trains was tested at four rail sections (Sections A, B, C, and D). The grinding speed was $12-13 \mathrm{~km} / \mathrm{h}$, and the grinding motor of the grinding train was set for active grinding at a rotating speed of $3400-3600 \mathrm{rpm}$. Grinding of the rail was mainly realized through the contacting edge of the grinding stone with the steel track, while it moved along the longitudinal direction of the rail, as shown in Figure 7.

When the grinding stone has a vertical ( $x$-axis) runout, the scratch interval can be calculated using.

$$
\begin{aligned}
\lambda & =\frac{v}{f} \\
& =\frac{((12 \sim 13) \times 1000) / 3.6}{((3400 \sim 3600)) / 60} \\
& =56-64 \mathrm{~mm} .
\end{aligned}
$$

As Figure 8 shows, regular scratch marks at intervals of approximately $60 \mathrm{~mm}$ appeared on the rail surface after grinding in Section A. This is consistent with the calculated results from Equation (1).
There are two types of high-speed passenger vehicles in Section A of the line, with axle weights of $13 t$ and $17 t, 105$ pairs of vehicles passing through every day, and a total of 75 million gross tons (MGT) passing through each year. The vehicle running speed was $300 \mathrm{~km} / \mathrm{h}$. For the track, a CRTS III track slab and WJ-8 fastening system were used, and the vertical stiffness of the fastening system was $20-40 \mathrm{kN} / \mathrm{mm}$. The rail irregularity investigation revealed that, owing to the previous grinding-caused corrugation marks at a wavelength of $60 \mathrm{~mm}$, scratch marks at a wavelength of approximately $60 \mathrm{~mm}$ could be clearly seen on the rail surface even after the present grinding (Figure 9). On the $87^{\text {th }}$ day after grinding, the roughness level at a wavelength smaller than $20 \mathrm{~mm}$ was higher than that before grinding. On the $202^{\text {nd }}$ day, the roughness level was lower than that on the $87^{\text {th }}$ day owing to the wear caused by wheel-rail contact. However, the characteristics of the initial rail corrugation at a wavelength of $63 \mathrm{~mm}$ were retained.

3.2. Simulation of Rail Grinder Dynamic Characteristic. To further investigate the grinding-caused rail corrugation at a wavelength of approximately $60 \mathrm{~mm}$, the rail-grinding procedures applied to the studied sections were simulated using a dynamic simulation model for rail-grinding trains. The reasons for the formation of rail grinding caused regular scratch marks on the steel rail track surface were analyzed by considering the impact of the vertical vibration of the 


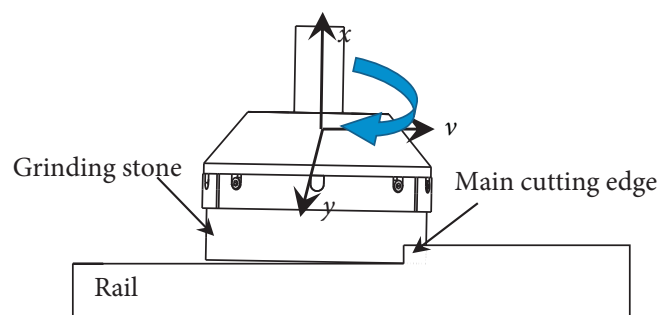

FIGURE 7: Schematic diagram of grinding mechanism of the grinding stone.

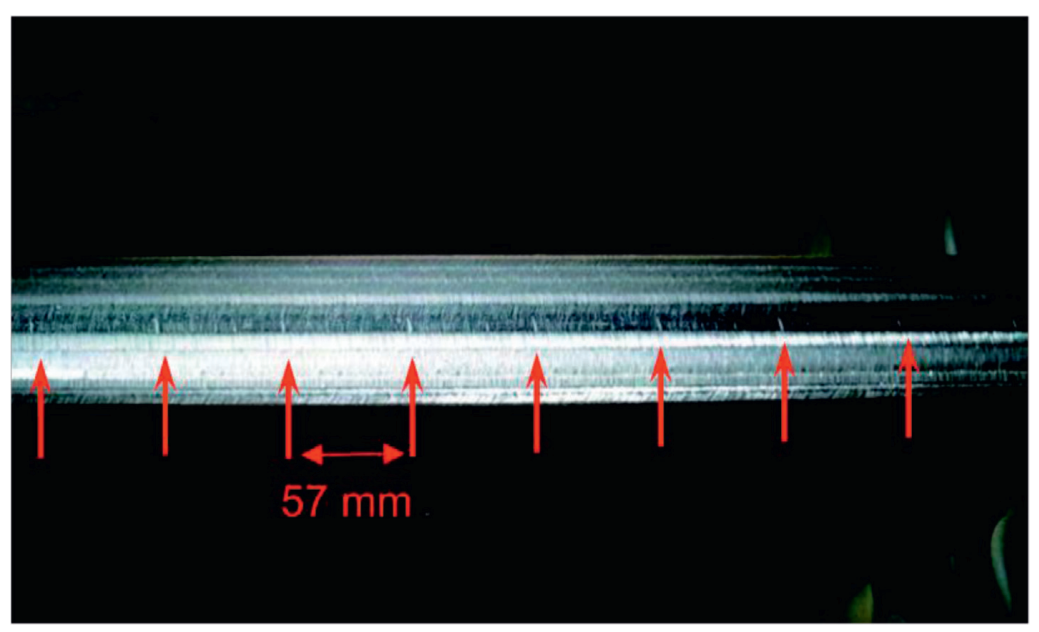

FIgURE 8: Grinding marks after rail grinding.

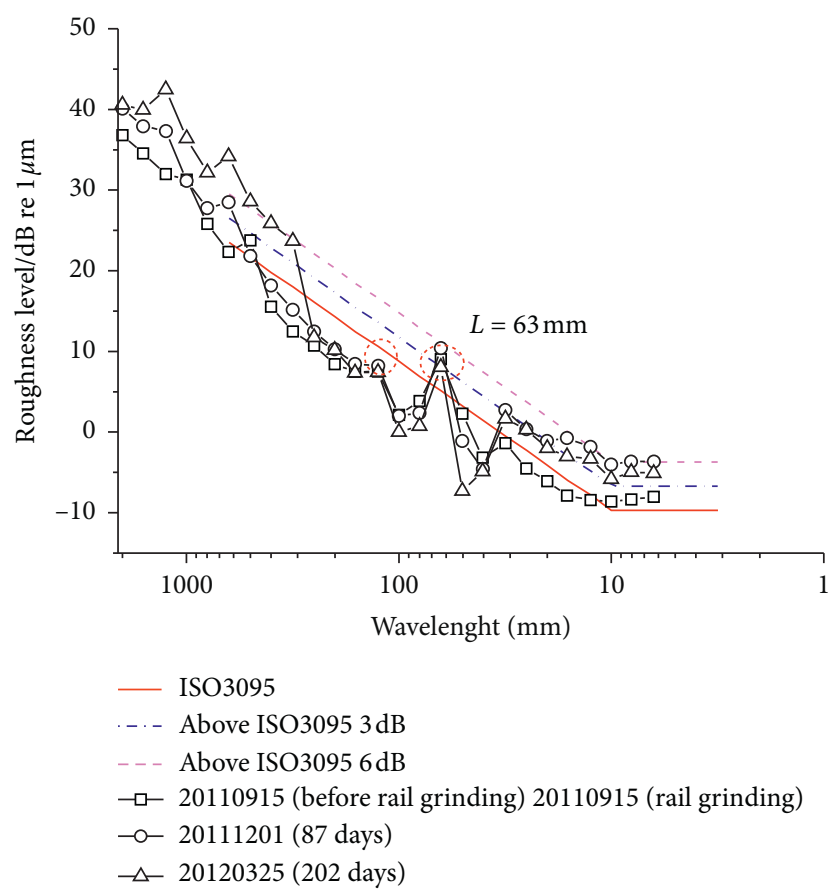

Figure 9: Development of corrugation after rail grinding in left rail. 
grinding stone on the dynamic characteristics of the grinding train.

The model (Figure 10) was built using UM dynamic analysis software and included 49 rigid bodies: 1 coach, 2 bogie frames, 4 wheelsets, 8 axle boxes, 8 independent wheels, 2 grinder bogies, 8 grinder carriages, and 16 grinding motors. The wheel profile of the rail-grinding train is called $\mathrm{LM}$, the independent wheel profile in the grinder bogie is referred to as GW (Figure 11), and the rail profile is CN 60 . The back-to-back distance of the wheelset was $1353 \mathrm{~mm}$, which is the same as the back-to-back distance of the independent wheels. The tangential contact solution in the dynamic simulation was based on Kalker's simplified theory implemented with a FASTSIM algorithm, and the vertical contact solution was based on the Hertz theory. The coefficient of friction was assumed to be constant at a value of 0.3 . The solving time step was $0.0001 \mathrm{~s}$ with the Park solution algorithm for the direct integration of nonlinear structural dynamic equations.

The bogie of the rail-grinding car was similar to that of the Y25 bogie of the freight car. A reduction in the vibration was realized using springs and friction plates, and the body and bogies were linked by the core plate on the rail-grinding train. The side bearing also reduced the vibration. The structural elasticity of all the bogie components was neglected. All force elements were modeled as viscoelastic force elements, considering all mechanical nonlinear characteristics (e.g., primary friction pairs, side bearings, and core disks).

A rail grinder is the core component of a rail-grinding train. This rail grinder was directed by four independent wheels and supported by a grinder frame (carriage). Inside the frame, there were four grinder cradles, each of which had two deflection cylinders on the sides to control the deflection angle of the motor. Two hoisting pneumatic cylinders were equipped to lift and drop the grinding motor in each cradle. Each grinder was connected to the grinding train body by lifting cylinders at the four corners of the frame. The structure is shown in Figure 12.

In the simulation model, guide wheels assembled in completely independent pairs were installed on the grinding car frame through a fixed connection. The frame and car body were connected through the lifting cylinders and the traction rod with a design that considered the stiffness and damping elements. After the angle of the cradle was fixed, the deflection cylinder and the car frame were connected through the stiffness and damping elements.

Considering actual conditions, the hoisting mechanism of the grinder motor was designed to have a standard hexagonal structure, in which the grinder cradle and motor were installed on opposite sides. This design allowed upand-down movements of the motor via the operation of hoisting pneumatic cylinders that act as stiffness and damping elements. The grinder motor that contacts the rail surface via the contact elements can impose a dynamic force on the grinding stone to simulate the cutting force during the actual rail-grinding process.
In typical hydraulic systems, hydraulic oil is generally considered an absolutely rigid body that is incompressible; thus, the impact caused by its compression in light-loaded and slow-motion systems is often negligible. However, under dynamic high-loading conditions or in a fast-acting servo system, the stiffness of the hydraulic system is often a limiting factor in system performance. Therefore, this should be considered in future studies. The hydraulic system in a grinding car is a dynamic high-loaded servo hydraulic system, for which the effect of stiffness should be considered.

To determine the hydraulic stiffness of a grinding car control system, it is necessary to consider the volume of hydraulic oil in both the cylinder and the pipelines between the cylinder and the hydraulic servo valves [44]. Therefore, the following equation was used:

$$
C_{T}=E \cdot\left[\frac{A_{1}^{2}}{V_{L 1}+V_{L 2}}+\frac{A_{2}^{2}}{V_{L 2}+V_{\text {right }}}\right] \text {, }
$$

where $C_{T}$ is the hydraulic rigidity, $E$ is the hydraulic oil volume elastic modulus, $V_{\text {left }}$ and $V_{\text {right }}$ are the hydraulic oil volumes on the left and right sides of the hydraulic cylinder, respectively, $A_{1}$ and $A_{2}$ are the piston areas on the left and right sides of the hydraulic cylinder, respectively, and $V_{L 1}$ and $V_{L 2}$ are the hydraulic oil volumes in the pipeline connected to the left and right sides of the cylinder, respectively.

For hydraulic cylinders with sides that have dissimilar areas, if the area and hydraulic oil volume ratios of the two sides of the hydraulic cylinder are not extremely large, the minimum stiffness is assumed to occur at the midpoint of the stroke.

Subsequently, the calculated stiffness is incorporated into the simulation model. To investigate the grinding process of the grindstone on the rail, their interaction was simulated using white noise excitation. Similarly, to determine the grinding performance on the rail surface, the same method was used to simulate the interaction between the grinder wheel and rail track.

The vertical vibration frequency spectrum of the grinding motor was calculated, as shown in Figure 13. It can be seen that broadband excitation resulted in vibrational frequencies of $53-57 \mathrm{~Hz}$ in the vertical direction of the grinding motor. At speeds of $11-13 \mathrm{~km} / \mathrm{h}$, vibrations at such frequencies can cause grinding marks with a wavelength of $60 \mathrm{~mm}$ on the rail surface.

Next, the effect of the stiffness of the deflection cylinder on the vertical vibration frequency of the grinding motor was determined under different speed conditions at a fixed deflection angle. Figure 14 shows the relationship curves between the vibration frequency and the wavelength when the grinding speed increased from 3 to $15 \mathrm{~km} / \mathrm{h}$, and the stiffness of the deflection cylinder was in the range of $1 \times 10^{6}$ to $2 \times 10^{8} \mathrm{~N} / \mathrm{m}$. It can be seen that the vibration frequency varied with the stiffness of the deflection cylinder, thereby leading to different vibration wavelengths. When the 


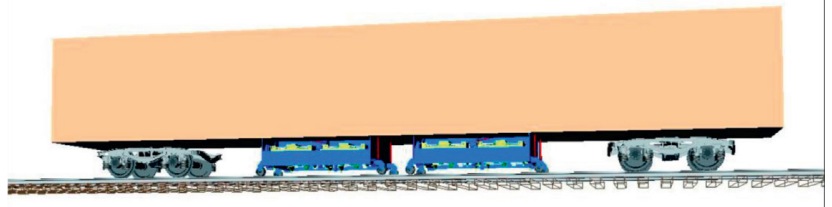

Figure 10: Multibody model of rail-grinding train.

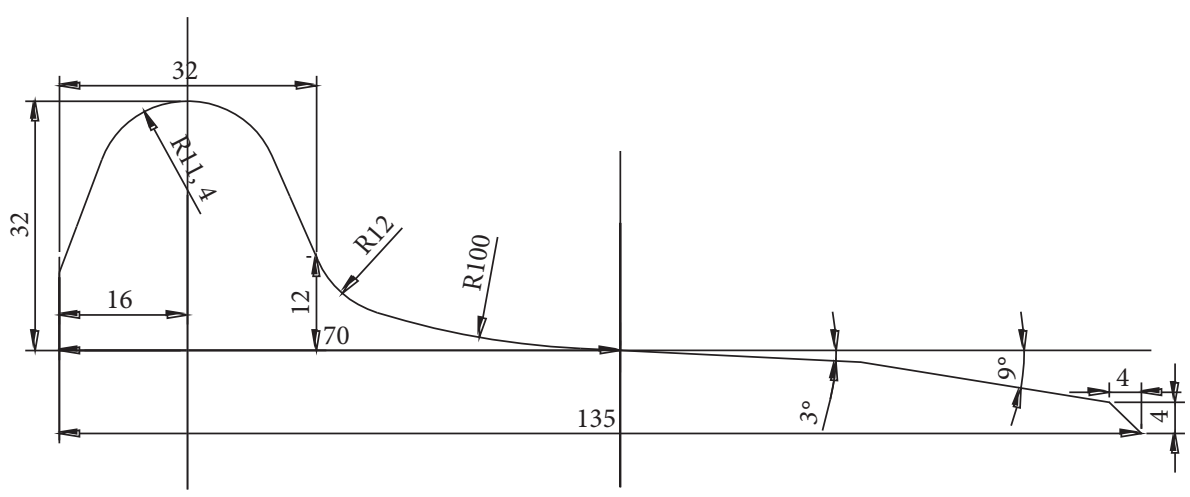

FIGURE 11: Wheel profile of rail grinder.

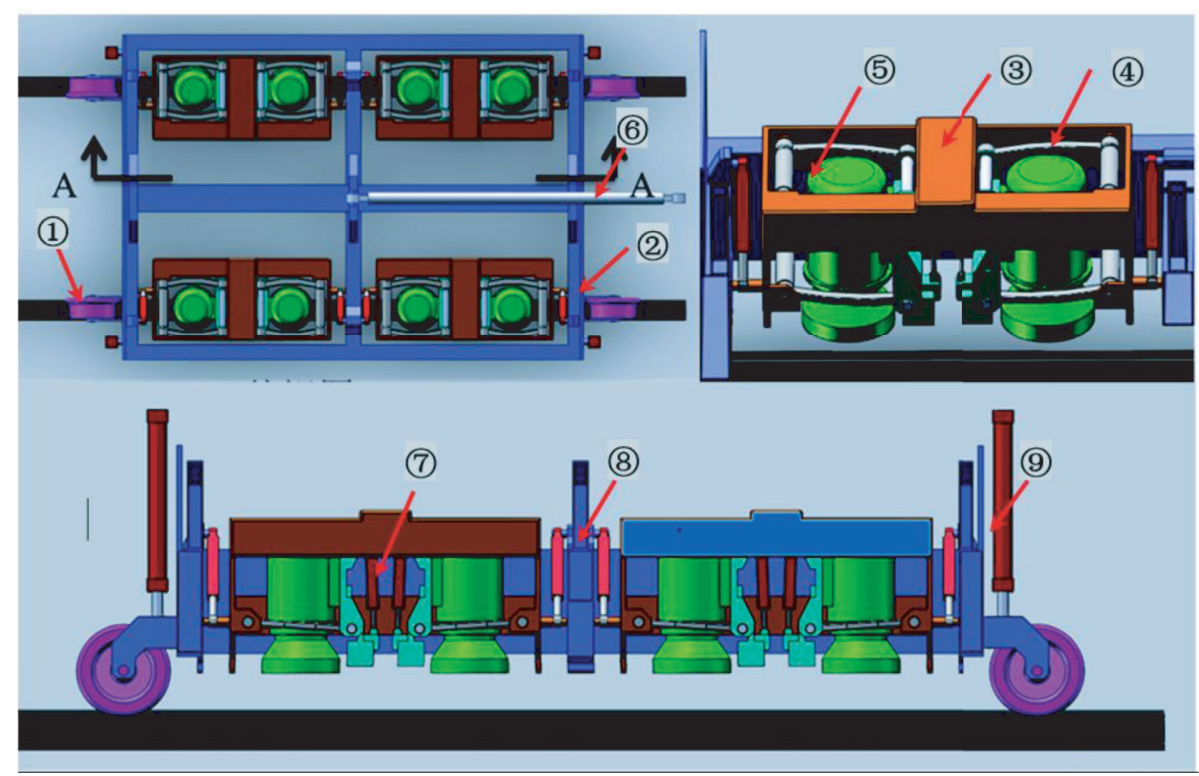

FIGURE 12: Multibody model of rail grinder(1) Rail grinder wheel. (2) Rail grinder bogie. (3) Grinder carriage. (4) Grinder motor hoisting mechanism. (5) Grinder motor. (6) Traction rod. (7) Hoisting pneumatic cylinder of grinder motor. (8) Grinder-carriage deflection cylinder. (9) Rail grinder bogie lifting cylinder. 


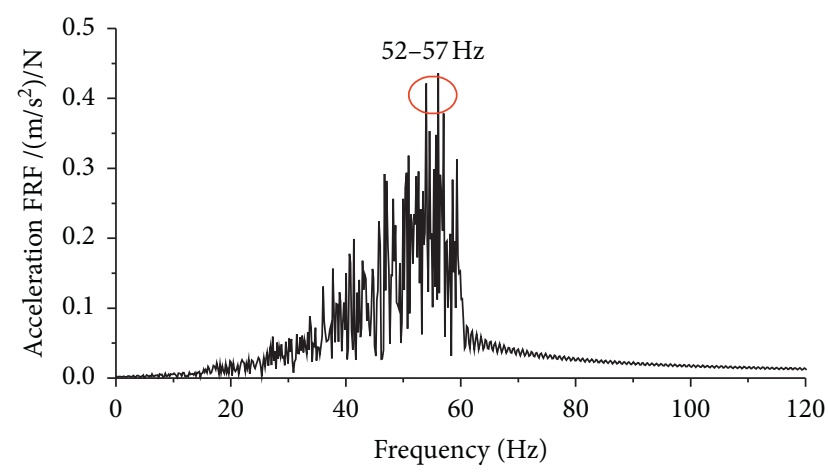

FIGURE 13: Vertical vibration spectrum of motor under white noise excitation.

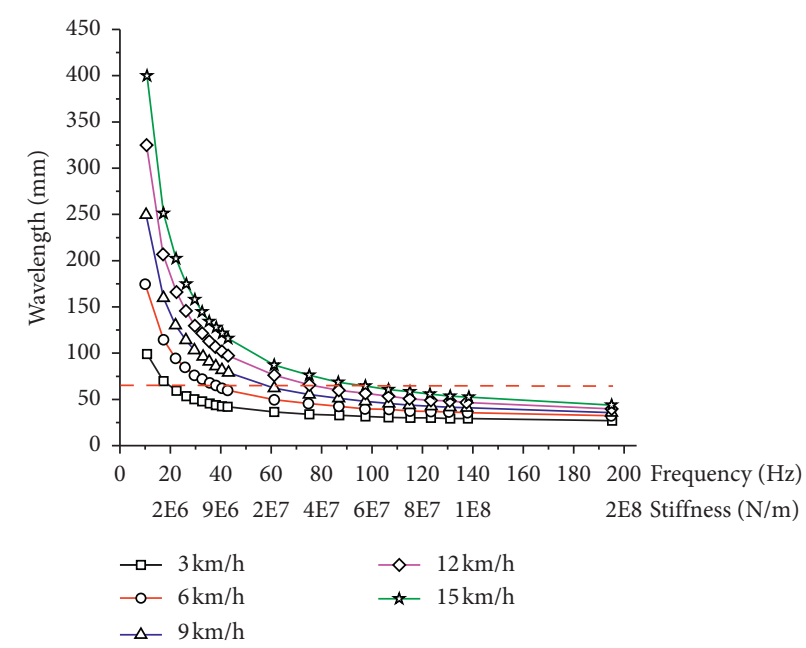

FIGURE 14: Length of grinding cracks under different stiffness levels of deflection cylinder and different grinding speeds.

stiffness was lower than $7 \times 10^{7} \mathrm{~N} / \mathrm{m}$, the grinding operation easily caused cracks with a wavelength of $60 \mathrm{~mm}$ on the rail surface.

\section{Testing and Verification of Vehicle and Track Vibration Characteristics}

4.1. Vibration Frequency-Response Test of the Rail Grinder. To verify the dynamic modeling and simulation results and further determine the vibration responses of the grinding system, force hammer tests were conducted on the grinding unit of a grinding train (Figure 15). The frequency-response function (FRF) of the system was obtained based on the relationship between the input excitation and the output response at specific frequencies. The FRF, which reflects the relationship between the input and output of a system, is an important frequency-domain characteristic parameter of the system and can be used to identify modal parameters.

The FRF of a structure can be measured by applying excitation to the structure. The force hammer and vibrating table tests are two common excitation methods. The former was utilized in this study, as it is fast and convenient, using a force hammer (Model 8206-002, B \& K Co.) and a 12channel data acquisition system (B \& K Co.).

The hammer was used in locations within the grinding unit that were likely to be excited during actual operation, which were set as excited points and sources of excitation. In this study, six excited points (guide wheel, end of the frame, midpoint of the frame, point at $1 / 4$ of the length of the frame, connection point of the vehicle body, and ground) were selected (Figure 16). The guide wheel was selected as an excited point to detect the vertical responses of the ground under the interference of rail-surface irregularities when the grindstone and rail track are in contact.

The connection point between the frame and the car body was selected as an excited point to test the vertical effect on the ground by vibrations of the car body at different frequencies. The end of the frame, midpoint of the frame, and point at $1 / 4$ of the length of the frame were selected to examine the effect of the frame's self-vibrations on the vertical vibration of the ground. In addition, this selection considered the effects of rail-surface irregularities and grinding operations on the vertical vibration of the ground stone when the grindstone contacts the rail track during grinding. 

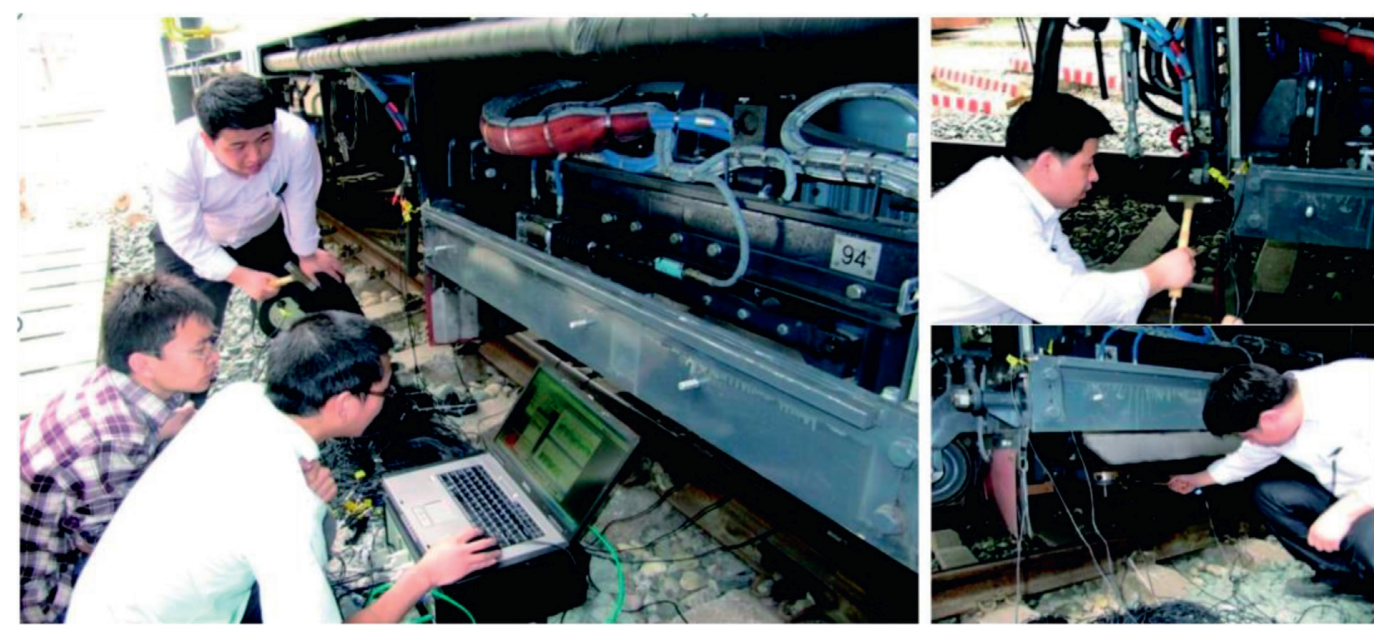

FIGURE 15: On-site vibration test of a rail-grinding train.

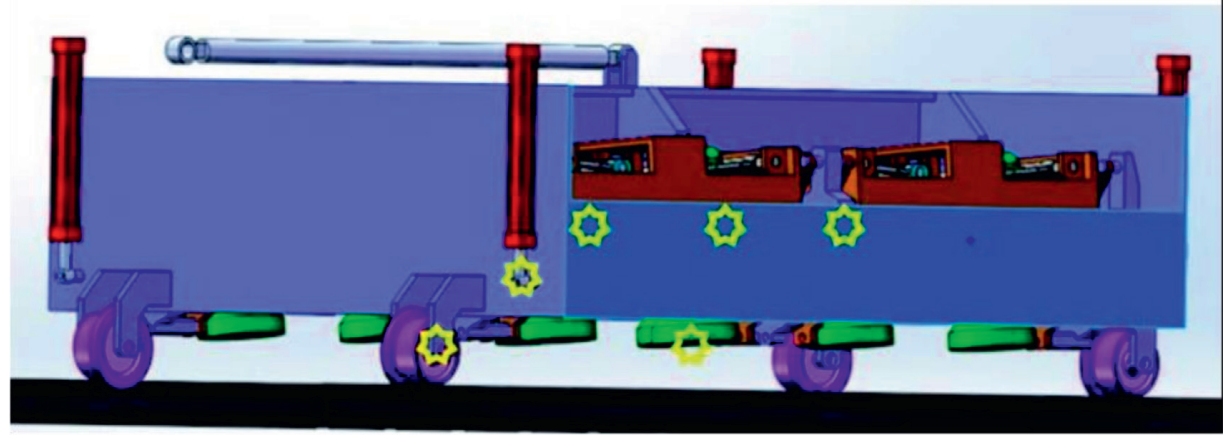

Figure 16: Excited points for different components of rail grinder.

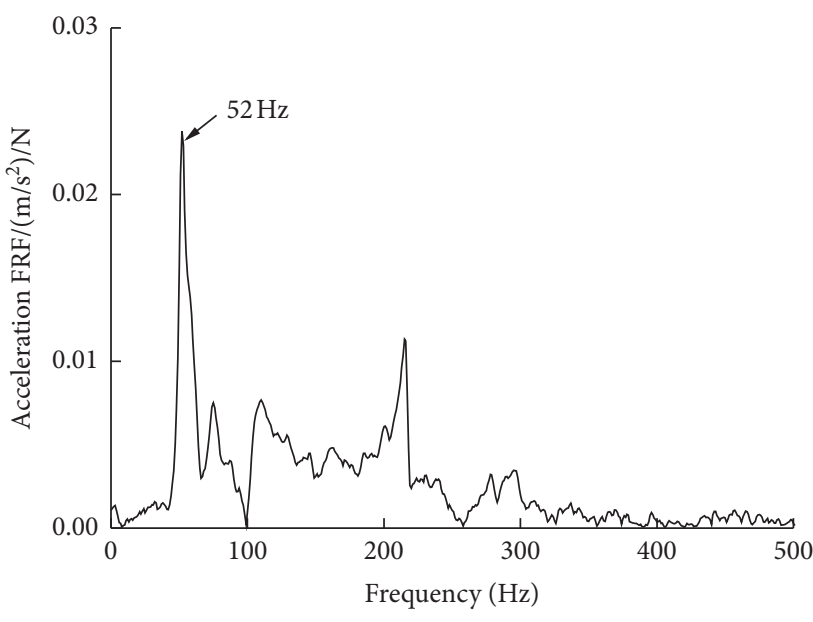

— Knock grinder bogie

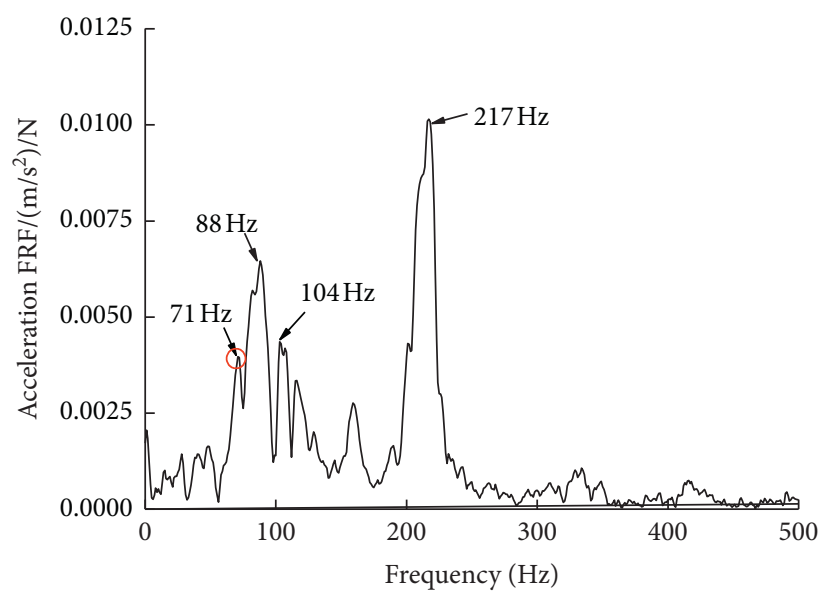

— Knock wheel

(a)

(b)

Figure 17: Continued. 


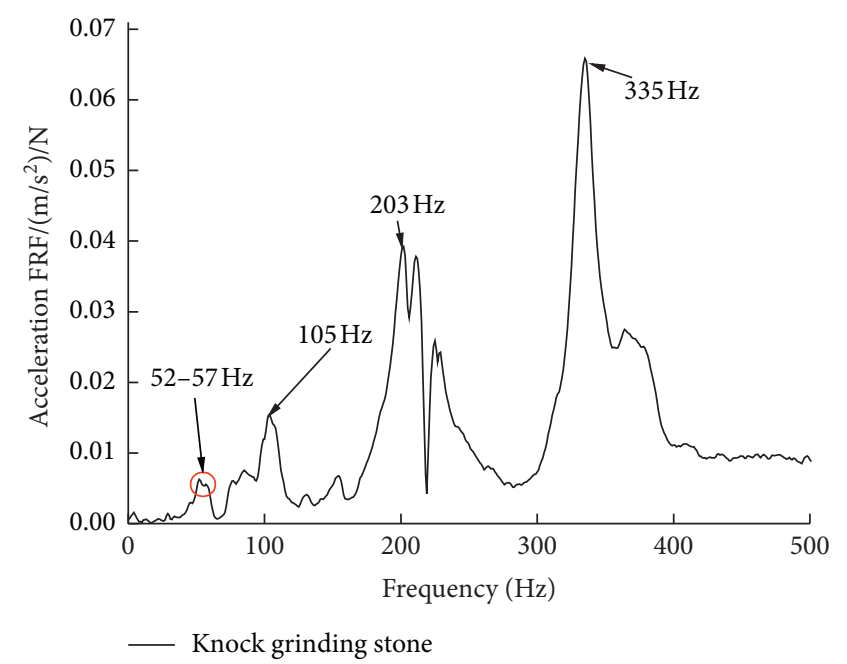

(c)

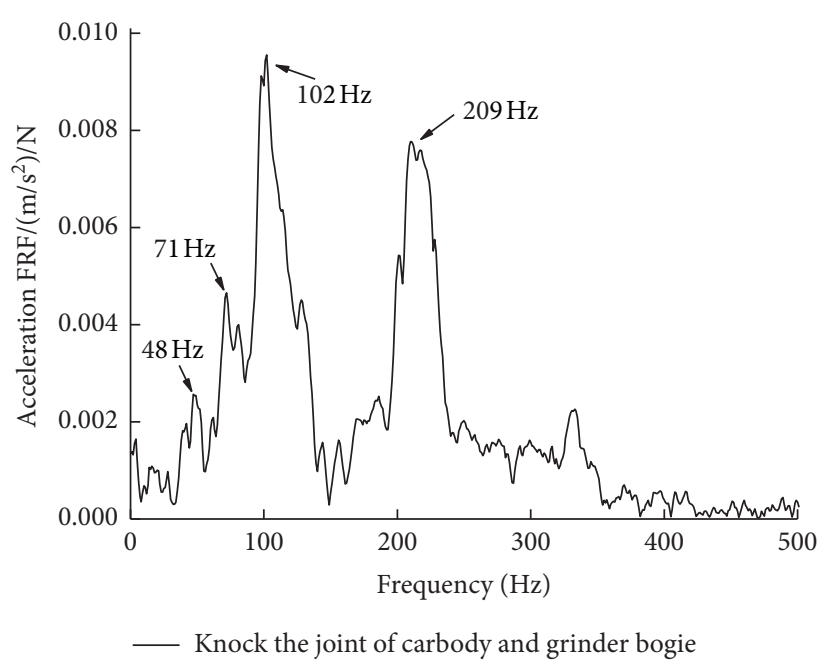

(d)

FIGURE 17: Acceleration frequency response of different components of the rail grinder. (a)Exciting the grinder bogie. (b) Exciting the wheel. (c) Exciting the grinding stone. (d) Exciting the joint of the car body and grinder bogie.

Acceleration sensors were used to detect the responses at the end of the frame and grindstone along the vertical, transverse, and longitudinal directions. Figure 17 shows the vertical responses of the grindstone under different excitations. The grindstone vertically vibrated at dominant frequencies in the range of $50-60 \mathrm{~Hz}$ in response to the vertical knocking on the grinding car frame and grindstone, and at significant frequencies of approximately $48 \mathrm{~Hz}$ and $70 \mathrm{~Hz}$ when the guide wheel and the connection point between the car frame and body were knocked, respectively. This result is consistent with the frequency of grinding marks caused by the grinding car.

4.2. Vibration Frequency-Response Test of the Track. Referring to the research of Professor Sageghi [45], the track structure parameters have a certain influence on the track geometric irregularity. To clarify the relationship between the vibration frequency and the track resonance frequency, the acceleration frequency response of the track on the corrugation section was investigated using the hammering impact method. The test results in Section A of Mr. Gu's doctoral dissertation is quoted here, as shown in Figures 18 and 19 [46].

Figures 18 and 19 depict the vertical acceleration transfer functions of the track-supporting sleeper and steel track segments above and in the middle of the sleeper spans when the track segment above the sleeper and when the track in the middle of the track spans were vertically knocked, respectively.

As shown in Figure 18, when the excitation was applied to the segment above the fastener (i.e., when the wheel run through the top of the fastener), the track segment above the fastener showed relatively more sensitive frequency ranges of $130-150 \mathrm{~Hz}, 810 \mathrm{~Hz}, 1000 \mathrm{~Hz}$, and $1150-1270 \mathrm{~Hz}$. Similarly, Figure 19 shows that when the excitation was applied to the middle of the track span (i.e., when the wheel was running through the middle of a track span), the part of the track in the middle of the span had relatively more sensitive frequency ranges of $130-150 \mathrm{~Hz}, 700-820 \mathrm{~Hz}, 920 \mathrm{~Hz}$, and $1000-1050 \mathrm{~Hz}$.

The dominant wavelengths of the rail corrugation observed during the on-site tests were $50-65 \mathrm{~mm}$ and $100-125 \mathrm{~mm}$. The average train speed passing through the corrugated rail was $270 \mathrm{~km} / \mathrm{h}$. Correspondingly, the frequencies of trains passing through the corrugated rail were as follows:

$$
\begin{aligned}
f_{1} & =\frac{v}{\lambda} \\
& =\frac{(270 \times 1000) / 3.6}{50 \sim 65} \\
& =1150-1500 \mathrm{~Hz}, \\
f_{2} & =\frac{v}{\lambda}=\frac{(270 \times 1000) / 3.6}{100 \sim 125} \\
& =600-750 \mathrm{~Hz} .
\end{aligned}
$$

The vertical pinned-pinned resonant frequency of the track and the passing frequency of $1150-1500 \mathrm{~Hz}$ of trains on the corrugated rail with a dominant corrugation wavelength of 50-65 mm were similar, which can lead to a resonance. This is consistent with the on-site observation, in which the track showed vertical flexural vibrations mostly in the frequency range of $1150-1270 \mathrm{~Hz}$. In other words, the frequency range of vertical flexural vibrations was similar to the passing frequency of $1150-1500 \mathrm{~Hz}$ of trains on corrugated rail with a dominant corrugation wavelength of 50-65 $\mathrm{mm}$.

Thus, the passing frequency was comparable to the vertical pinned-pinned resonant frequency of the track, indicating that the development of rail corrugation with a characteristic wavelength of $50-65 \mathrm{~mm}$ is related to the 


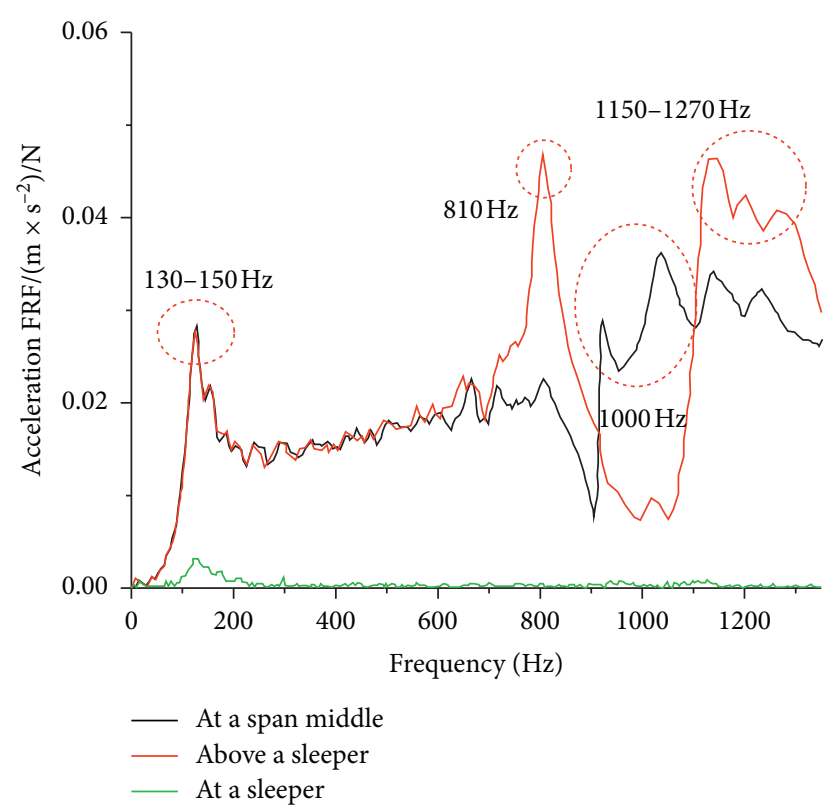

Figure 18: Vertical acceleration transfer functions when a vertical excitation is applied to the track segment above the sleeper.

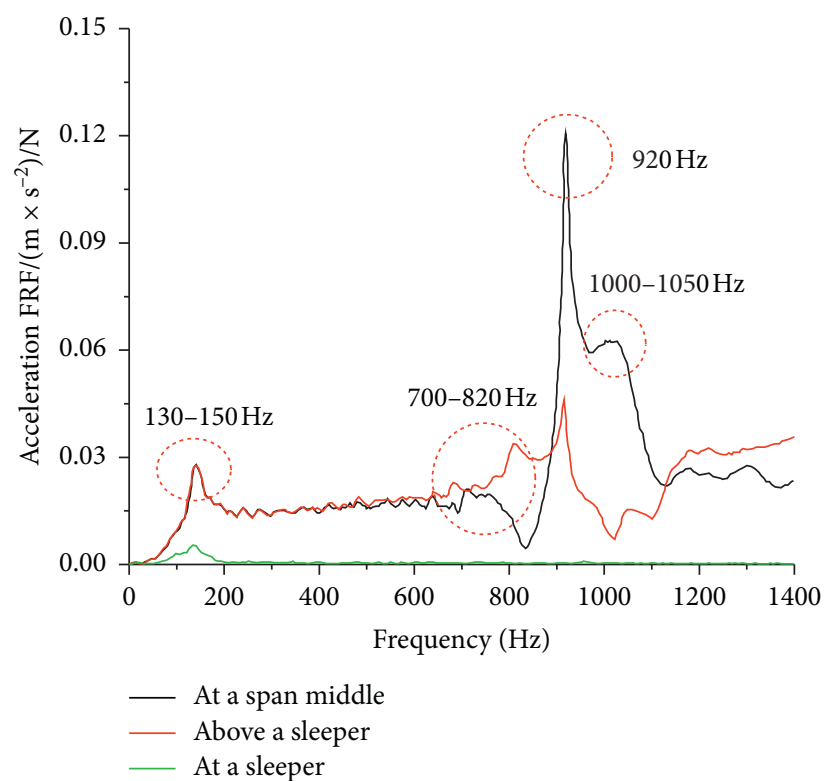

Figure 19: Vertical acceleration transfer functions when a vertical excitation is applied to the track segment in the middle of the sleeper spans.

vertical flexural resonance (mainly the vertical pinnedpinned resonance) of the track. In addition, the frequency range of vertical resonances of this track $(700-820 \mathrm{~Hz})$ was similar to the passing frequency of $600-750 \mathrm{~Hz}$ for rail corrugation with a secondary wavelength of $125-160 \mathrm{~mm}$. This indicates that the generation of rail corrugation with a secondary wavelength of $100-125 \mathrm{~mm}$ is related to the $700-820 \mathrm{~Hz}$ resonance of the track.

In conclusion, the significant wavelength of rail corrugation is related to the vertical pinned-pinned resonance in the vibration characteristics of the track structure, and the secondary wavelength of rail corrugation is interrelated to the vertical resonance of the track slab [46]. Therefore, when the frequency of the wheel and rail excited by the grinding mark is consistent with the pinned-pinned frequency of the rail, rail corrugation may occur. Figure 9 shows the process of development of corrugation in the same testing section.

\section{Conclusions}

This study investigated the relationship between the grinding operation process and the development of rail 
corrugation by using on-site measurements to characterize rail corrugation, simulation models to analyze the dynamic characteristics of rail-grinding trains, and force hammer tests to further examine the vibration characteristics of grinding systems. The main conclusions and recommendations are as follows:

(1) Field investigations revealed that a grinding operation with a grinding train running at a speed of approximately $12-13 \mathrm{~km} / \mathrm{h}$ can easily cause regular wear marks with a wavelength of approximately $60 \mathrm{~mm}$ on the rail surface;

(2) Using a dynamic simulation model of grinding trains and force hammer tests on different vibration points, this study revealed that the operation of a grinding train can cause vibrations in the ground at a frequency of $60 \mathrm{~Hz}$;

(3) The grinder with the condition of hydraulic system stiffness and the interval of grinding marks can be changed by changing the grinding speed;

(4) When the frequency of the wheel and rail excited by the grinding mark is consistent with the pinnedpinned frequency of the rail, rail corrugation may occur.

Given the effects of a grinding operation and the natural vibration characteristics of grinding trains, regular grinding marks can trigger the pinned-pinned resonance frequency of the rail tracks, thereby accelerating the formation and development of rail corrugation [47]. It is recommended to adjust the grinding speed to produce certain irregularities on the rail surface based on the traveling speed of trains on the rail and thus avoid the risk caused by the pinned-pinned resonance of the track.

\section{Data Availability}

The data used to support the findings of this study are included within the article.

\section{Conflicts of Interest}

The authors declare that they have no conflicts of interest.

\section{Acknowledgments}

This work was supported by the National Natural Science Foundation of China (Grant no. 52002343) and the Science and Technology Program of Sichuan Province of China (Grant no. 2019YFH0053).

\section{References}

[1] J. Sadeghi and A. Hasheminezhad, "Correlation between rolling noise generation and rail roughness of tangent tracks and curves in time and frequency domains," Applied Acoustics, vol. 107, pp. 10-18, 2016.

[2] L. Auersch, "Simple and fast prediction of train-induced track forces, ground and building vibrations," Railway Engineering Science, vol. 28, no. 3, pp. 232-250, 2020.
[3] X. S. Jin, W. Li, Z. F. Wen, H. Y. Wang, and X. Z. Sheng, "An investigation into rail corrugation, its mechanisms and effects on the dynamic behavior of metro trains and tracks in China," International Journal of Railway Technology, vol. 5, no. 3, pp. 1-29, 2016.

[4] J. Sadeghi, A. Khajehdezfuly, H. Heydari, and H. Askarinejad, "Development of railway ride comfort prediction model: incorporating track geometry and rolling stock conditions," Journal of Transportation Engineering, Part A: Systems, vol. 146, no. 3, Article ID 04020006, 2020.

[5] J. Sadeghi, A. Khajehdezfuly, M. Esmaeili, and D. Poorveis, "Investigation of rail irregularity effects on wheel/rail dynamic force in slab track: Comparison of two and three dimensional models," Journal of Sound and Vibration, vol. 374, no. 21, pp. 228-244, 2016.

[6] X. Jin, Z. Wen, K. Wang, and W. Zhang, "Effect of a scratch on curved rail on initiation and evolution of rail corrugation," Tribology International, vol. 37, no. 5, pp. 385-394, 2004.

[7] Y. Sato, A. Matsumoto, and K. Knothe, "Review on rail corrugation studies," Wear, vol. 253, no. 1-2, pp. 130-139, 2002.

[8] J. C. O. Nielsen, R. Lundon, A. Johansson, and T. Vernersson, "Train-track interaction and mechanisms of irregular wear on wheel and rail surfaces," Vehicle System Dynamics, vol. 40, no. 1-3, pp. 3-54, 2003.

[9] W. Li, X. Du, H. Wang et al., "Investigation into the mechanism of type of rail corrugation of metro," Journal of Mechanical Engineering, vol. 49, no. 16, pp. 26-31, 2013.

[10] D. R. Ahlbeck and L. E. Daniels, "Investigation of rail corrugations on the baltimore metro," Wear, vol. 144, pp. 197210, 1992.

[11] E. Tassilly and N. Vincent, "A linear model for the corrugation of rails," Journal of Sound and Vibration, vol. 150, no. 1, pp. 25-45, 1991.

[12] J. Kalousek and K. L. Johnson, “An investigation of short pitch wheel and rail corrugations on the Vancouver mass transit system," Proceedings of the Institution of Mechanical Engineers, Part F: Journal of Rail and Rapid Transit, vol. 206, no. 26, pp. 127-135, 1992.

[13] T. X. Wu and D. J. Thompson, "An investigation into rail corrugation due to micro-slip under multiple wheel/rail interactions," Wear, vol. 258, no. 7-8, pp. 1115-1125, 2005.

[14] T. X. Wu, "Effects on short pitch rail corrugation growth of a rail vibration absorber/damper," Wear, vol. 271, no. 1-2, pp. 339-348, 2011.

[15] X. S. Jin, Z. F. Wen, K. Y. Wang, Z. R. Zhou, Q. Y. Liu, and C. H. Li, "Three-dimensional train-track model for study of rail corrugation," Journal of Sound and Vibration, vol. 293, no. 3-5, pp. 830-855, 2006.

[16] X. Jin, Z. Wen, W. Zhang, and Z. Shen, "Numerical simulation of rail corrugation on a curved track," Computers \& Structures, vol. 83, no. 25-26, pp. 2052-2065, 2005.

[17] X. Jin, F. Wen, and K. Wang, "Effect of high-frequency vertical vibration of track on formation and evolution of corrugations," Tsinghua Science and Technology, vol. 9, no. 3, pp. 274-280, 2004.

[18] Z. Wen, X. Jin, X. Xiao, and R. Zhou, "Effect of a scratch on curved rail on initiation and evolution of plastic deformation induced rail corrugation," International Journal of Solids and Structures, vol. 45, no. 7-8, pp. 2077-2096, 2008.

[19] G. Xie and S. D. Iwnicki, "A rail roughness growth model for a wheelset with non-steady, non-Hertzian contact," Vehicle System Dynamics, vol. 48, no. 10, pp. 1135-1154, 2010. 
[20] G. Xie and S. Iwnicki, "Simulation of wear on a rough rail using a time-domain wheel-track interaction model," Wear, vol. 265, no. 11-12, pp. 1572-1583, 2008.

[21] C. Frederick, "A rail corrugation theory," in Proceedings Of the 2nd International Conference Of Contact Mechanics And Wear Of Rail System, University of Waterloo Press, Waterloo, Canada, July 1986.

[22] K. Hempelmann and K. Knothe, "An extended linear model for the prediction of short pitch corrugation," Wear, vol. 191, no. 1-2, pp. 161-169, 1996.

[23] A. Igeland and H. Ilias, "Rail head corrugation growth predictions based on non-linear high frequency vehicle/track interaction," Wear, vol. 213, no. 1-2, pp. 90-97, 1997.

[24] Z. F. Wen, "Study on rail corrugation," Doctor Degree Dissertation, Southwest Jiaotong University, Chengdu, China, 2006.

[25] S. L. Grassie and J. A. Elkins, "Corrugation on north American transit lines," Vehicle System Dynamics, vol. 28, no. 1, pp. 5-17, 1998.

[26] R. I. Mair and M. I. E. Aust, Natural Frequency of Rail Track and its Relationship to Rail Corrugation, Civil Engineering Transactions, Barton, Australia, 1977.

[27] E. Tassilly and N. Vincent, "Rail corrugations: analytical model and field tests," Wear, vol. 144, no. 1-2, pp. 163-178, 1991.

[28] G. Diana, F. Cheli, S. Bruni, and A. Collina, "Experimental and numerical investigation on subway short pitch corrugation," Vehicle System Dynamics, vol. 28, no. 1, pp. 234-245, 1998.

[29] S. L. Grassie, "Rail corrugation: characteristics, causes, and treatments," Proceedings of the Institution of Mechanical Engineers, Part F: Journal of Rail and Rapid Transit, vol. 223, no. 6, pp. 581-596, 2009.

[30] X. Liu and P. Wang, "Investigation of the generation mechanism of rail corrugation based on friction induced torsional vibration," Wear, vol. 468-469, pp. 1-9, 2021.

[31] X. Jin, X. Xiao, Z. Wen, and Z. Zhou, "Effect of sleeper pitch on rail corrugation at a tangent track in vehicle hunting," Wear, vol. 265, no. 9-10, pp. 1163-1175, 2008.

[32] P. A. Bellette, P. A. Meehan, and W. J. T. Daniel, "Effects of variable pass speed on wear-type corrugation growth," Journal of Sound and Vibration, vol. 314, no. 3-5, pp. 616-634, 2008.

[33] H. Ilias, "The influence of $r$ stiffness on wheelset/track interaction and corrugation growth," Journal of Sound and Vibration, vol. 227, no. 5, pp. 935-948, 1999.

[34] J. I. Egana, J. Vinolas, and M. Seco, "Investigation of the influence of rail pad stiffness on rail corrugation on a transit system," Wear, vol. 261, no. 2, pp. 216-224, 2006.

[35] X. S. Jin, Z. F. Wen, and K. Y. Wang, "Effect of track irregularities on initiation and evolution of rail corrugation," Journal of Sound and Vibration, vol. 285, no. 1-2, pp. 121-148, 2005.

[36] Z. Wen and X. Jin, "Effect of track lateral geometry defects on corrugations of curved rails," Wear, vol. 259, no. 7-12, pp. 1324-1331, 2005.

[37] E. G. Vadillo, J. Tárrago, G. G. Zubiaurre, and C. A. Duque, "Effect of sleeper distance on rail corrugation," Wear, vol. 217, no. 1, pp. 140-145, 1998.

[38] X. S. Jin and Z. F. Wen, "Effect of discrete track support by sleepers on rail corrugation at a curved track," Journal of Sound and Vibration, vol. 315, no. 1-2, pp. 279-300, 2008.

[39] A. Böhmer and T. Klimpel, "Plastic deformation of corrugated rails-a numerical approach using material data of rail steel," Wear, vol. 253, no. 1-2, pp. 150-161, 2002.
[40] K. H. Oostermeijer, "Review on short pitch rail corrugation studies," Wear, vol. 265, no. 9-10, pp. 1231-1237, 2008.

[41] X. Jin, X. Du, J. Guo, and D. Cui, "State of arts of research on rail grinding," Journal of Southwest Jiaotong University, vol. 45, no. 1, pp. 1-11, 2010.

[42] A. M. Zarembski, On the Benefits of Rail Maintenance Grinding, AREA Bulletin, Washington, DC, USA, 1988.

[43] W. R. Tyfour, "Predicting the effect of grinding corrugated rail surface on the wear behavior of pearlitic rail steel," Tribology Letters, vol. 29, no. 3, pp. 229-234, 2008.

[44] Y. F. Dai, "Stiffness calculation of hydraulic cylinder," Nonferrous Metals Design, vol. 26, no. 1, pp. 61-63, 1999.

[45] J. Sadeghi and H. Askarinejad, "An investigation into the effects of track structural conditions on railway track geometry deviations," Proceedings of the Institution of Mechanical Engineers, Part F: Journal of Rail and Rapid Transit, vol. 223, no. 4, pp. 415-425, 2009.

[46] Y. Gu, "Study on the mechanism of rail corrugation on highspeed railway unballasted track," Doctor Degree Dissertation, Beijing Jiaotong University, Beijing, China, 2017.

[47] Q. Zhou, F. Liu, Y. Zhang, C. Tian, and Y. Jie, "Solution for problem at wheel rail interface in high speed railway," China Railway Science, vol. 38, no. 5, pp. 1-7, 2017. 